\title{
Post-Traumatic Stress Reactions Following the March 11, 2004 Terrorist Attacks in a Madrid Community Sample: A Cautionary Note about the Measurement of Psychological Trauma
}

\author{
Carmelo Vázquez ${ }^{1}$, Pau Pérez-Sales ${ }^{2}$, and Georg Matt ${ }^{3}$ \\ ${ }^{1}$ Universidad Complutense de Madrid \\ ${ }^{2}$ Hospital La Paz (Madrid) and Grupo de Acción Comunitaria (GAC), Madrid \\ ${ }^{3}$ San Diego State University, USA
}

\begin{abstract}
Posttraumatic stress reactions related to the Madrid March 11, 2004, terrorist attacks were examined in a sample of Madrid residents $(N=503)$ 18-25 days after the attacks, using multiple diagnostic criteria and different cut-off scores. Based on the symptoms covered by the Posttraumatic Stress Disorder Checklist-Civilian (PCL-C; Weathers, Litz, Herman, Huska, \& Keane, 1993), rates of probable posttraumatic stress disorder (PTSD) ranged from $3.4 \%$ to $13.3 \%$. Taking into account additional criteria from the Diagnostic and Statistical Manual of Mental Disorders (American Psychiatric Association, 200; i.e., the impact of initial reaction and problems in daily functioning as a consequence of the traumatic event), only $1.9 \%$ of respondents reported probable PTSD. These results suggest that inferences about the impact of traumatic events on the general population are strongly influenced by the definition of traumatic response. Our findings also revealed that the magnitude of posttraumatic reactions is associated with several risk factors, including living close to the attacked locations, physical proximity to the attacks when they occurred, perception of one's life being at risk, intensity of initial emotional reactions, and being a daily user of the attacked train lines. The use of different cut-off scores did not affect the pattern of risk to develop traumatic stress. The implications of these results for public health policies related to terrorist attacks are discussed.
\end{abstract}

Keywords: Post traumatic stress disorder, trauma, PTSD, acute stress disorder, risk factors, September 11, terrorism

Se examinaron reacciones de estrés postraumático, empleando múltiples criterios diagnósticos y puntos de corte, en una muestra de la población de Madrid $(N=503), 18-25$ días después de los ataques terroristas de Madrid del 11 de marzo de 2004. En función del punto de corte seleccionado, los porcentajes de probable trastorno de estrés postraumático (TEPT) basado en el Posttraumatic Stress Disorder Checklist-Civilian (PCL-C; Weathers, Litz, Herman, Huska, \& Keane, 1993) fluctuaban entre el $3,4 \%$ y el $13,3 \%$. Al añadir a los síntomas de TEPT otros criterios del Manual Diagnóstico y Estadístico de Trastornos Mentales (American Psychiatric Association, 2000) requeridos para su diagnóstico (p. ej., el impacto de la reacción inicial y problemas en el funcionamiento cotidiano como consecuencia del evento traumático), sólo el 1,9\% presentaba un probable TEPT. Estos resultados demuestran que las inferencias acerca del impacto de eventos traumáticos en la población general pueden depender en gran parte de la definición y medida de la respuesta traumática. Nuestros resultados también revelaron que, aunque la magnitud de las reacciones postraumáticas se relacionaba con varios factores de riesgo (vivir cerca de los lugares atacados, proximidad física a los ataques cuando ocurrieron, percepción de amenaza para la propia vida, intensidad de las reacciones emocionales iniciales, y ser un usuario diario de las líneas de trenes atacadas), el uso de diferentes estrategias de punto de corte no afectó el patrón principal de riesgo para el desarrollo de estrés traumático. Se comentan las implicaciones de estos resultados para las políticas de la salud pública relacionadas con los ataques terroristas.

Palabras clave: trastorno de estrés posttraumático, trauma, TEPT, trastorno agudo de estrés, factores de riesgo, 11 de septiembre, terrorismo

This research was partially financed by a grant from the Pfizer Foundation (Spain). We want to thank Beatriz Armada for her continuous support of our project and Jesús Sanz, Sandro Galea, Chris Brewin, and Richard MacNally for their helpful comments on earlier versions of this manuscript. We are also indebted to María José Collado, Lourdes López and to many other students at the Facultad de Psicología (UCM) who volunteered to collaborate in gathering information for this research.

Address correspondence to: Carmelo Vázquez, Facultad de Psicología, Universidad Complutense, Campus de Somosaguas, 28223 Madrid (Spain). Telephone: (34) 91-3943131. Fax: (34) 91-3943189. E-mail: cvazquez@ psi.ucm.es 
Until the terrorist attacks of September 11, 2001 (S11), on American soil, there was scarce information on the psychological reactions of the general population, not necessarily affected in a direct manner by the events, subjected to massive attacks. For instance, in former similar events, such as the brutal bombing of a governmental building in Oklahoma City (USA) on April 19, 1995, in which 168 people died, the largest amount of the collected data was focused on the direct victims or on the people directly exposed to trauma (North, Nixon, Shariat et al., 1999). Nevertheless, there was little knowledge about the immediate reactions of the general population, the larger part of which was not directly exposed to the traumatic event. Despite the difficulties to conduct methodologically sound studies on the general population under these circumstances (see North \& Pfefferbaum, 2002), the S11 events opened a new way of research by addressing the immediate reactions to trauma in the general population.

The earliest studies on the immediate effects of the S11 attacks were conducted within 2-3 days after the incident (Murphy, Wismar, \& Freeman, 2003; Schuster et al., 2001), followed by a second wave of studies 1-2 months later (Blanchard et al., 2004; Galea et al., 2002; Schlenger et al., 2002; Silver, Holman, McIntosh, Poulin, \& Gil-Rivas, 2002). A same line of research was also followed after the Madrid March 11, 2004 (M11), attacks (Conejero, de Rivera, Páez, \& Jiménez, 2004; Miguel-Tobal, Cano-Vindel, Iruarrizaga, González, \& Galea, 2004; Muñoz, Crespo, Pérez-Santos \& Vázquez, 2004) and, more recently, on the London attacks on July 7, 2005 (Rubin, Brewin, Greenberg, Simpson, \& Wessely, 2005). Although some of these studies have focused on the most extreme responses, such as the development of a full posttraumatic stress response as measured by categories like the Post Traumatic Stress Disorder (PTSD), - for example, Galea et al., 2002; Miguel-Tobal et al., 2004-the majority has used a dimensional approach by including symptom scales that reflect different degrees of stress reactions (e.g., Blanchard et al.; Muñoz et al.; Murphy et al.; Rubin, Brewin, Greenberg, Simpson, \& Wessely, 2005; Schlenger et al.; Schuster et al.; Silver et al.). All these studies are making substantial contributions to our understanding of the short-term responses in the general populations directly or indirectly affected by terrorist attacks ${ }^{1}$. In addition, these studies are also adding to the literature on stress responses in populations not residing in the attacked areas but exposed through the intensive media coverage provided by TV, radio, and newspapers (Blanchard et al.; Murphy et al.; Schlenger et al.).

However, depending on the definition and measurement strategies of the psychological reactions, the results of these studies are quite disparate (see Table 1). This variability may be attributed to the specific characteristics of each event, the strategies of sample selection, and, perhaps more important, the use of different assessment strategies, which typically range from rather simple self-report symptom scales to clinical interviews following diagnostic criteria (Bryant \& Harvey, 2000; Norris, Byrne, Diaz, \& Kaniasty, 2001).

In regard to measurement strategies, researchers have typically used three different ways to assess the impact of these events on the general population. The first strategy, and probably the most frequently used, has been to use instruments that basically cover a number of symptoms related to traumatic stress reaction. One interesting example of this approach was carried out by scientists of the RAND Corporation by measuring between 3 to 5 days after the attack on the World Trade Center the psychological reactions in a representative sample of the nation (see Table 1). This paper was published on November, 15, 2001, in The New England Journal of Medicine, one of the publications with a larger impact factor in Medicine (Schuster et al., 2001). The study reported that $90 \%$ of the interviewed subjects experienced at least moderate levels of stress symptoms and $44 \%$ of the total sample reported having experienced at least one symptom of "substantial stress." In a second part of the same study, conducted 2 months after the attack, the authors found that $16 \%$ of those who had a substantial stress level in September 2001 still had that reaction in November of the same year (Stein et al., 2004). The initial conclusions of these studies were very alarming and suggested, according to these authors, the need for early psychological interventions, given that "by intervening as soon as symptoms appear, physicians, psychologists, and other clinicians may be able to help people to identify normal reactions and take steps to cope effectively" (Schuster et al., p. 1511). Likewise, they predicted that "the psychological effects of the recent terrorism are unlikely to disappear soon." However, a critical analysis of these studies may lead to different conclusions (see Vázquez, 2005). In fact, what the authors defined as "substantial stress" was simply to obtain a score of 4 ("quite a bit") or 5 ("extremely") in any of 5 selected items related to PTSD symptoms ${ }^{2}$.

1 For a review of other selected subsamples of affected people after the M11 attacks in Madrid, see the papers by Iruarrizaga, MiguelTobal, Cano-Vindel, \& González (2004) on the impact on victims and relatives, and González-Ordi, Miguel-Tobal, Cano-Vindel, \& Iruarrizaga (2004) on the impact on emergency personnel.

2 The items chosen were those reported as present by 50\% or more of the survivors of the bombing attack in Oklahoma City (North et al., 1999): 1) "Feeling very upset when something reminds you of what happened?"; 2) "Repeated, disturbing memories, thoughts, or dreams about what happened?"; 3) "Having difficulty concentrating?"; 4) “Trouble falling or staying asleep?"; 5) "Feeling irritable or having angry outbursts?”. 
In a study that addressed the initial stress reactions 923 days after the S11 attacks, Silver et al. (2002) found that $12.4 \%$ of their national representative sample at wave 1 showed high levels of symptoms, suggesting a probable acute stress disorder ${ }^{3}$. In a study conducted 2-3 weeks after the event, Muñoz et al. (2004) found that, in a Madrid representative sample of the general population, $47 \%$ of the subjects showed "significant symptoms of acute stress" (confusion, emotional estrangement, nightmares, avoidance of situations or places that remind one of the event, irritableness, nervousness..). Nevertheless, both studies based their results on self-reported questionnaires that do not strictly follow the Diagnostic and Statistical Manual of Mental Disorders (4 ${ }^{\text {th }}$ edition; American Psychiatric Association, 1994) diagnostic criteria for acute stress disorder (ASD). As far as we know, only the study of Blanchard et al. (2004) has evaluated the presence of probable DSM-IV (1994) cases of ASD, although it was based only on scorings of a questionnaire (see Table 1). In this study, in which three subsamples of university students participated after S11 in different areas of the USA, the results showed that the students of Albany (New York State) had a higher prevalence of probable ASD cases (28.0\%) than the students who were more distant, such as those who lived in Fargo (North Dakota)-9.7\%. Nevertheless, as we will discuss later, that one third of a university sample of students living in Albany (100 miles from Manhattan) might correspond to cases of a diagnosed mental disorder (i.e., ASD) seems to be a rather overestimated figure.

In our opinion, all these data about "substantial stress" or about "symptoms of acute stress," suggesting a widespread clinical disorder in the general population, might lead to an overestimation of the epidemiological needs unless a careful analysis of the data and measurement strategies is previously made. It does not seem that these figures, even if they are significant, correspond to a need for psychological intervention or that they truly correspond with clinical significant conditions, especially in the case of studies in which remarkably low diagnostic thresholds are used, and which are based on selfreport tools (Muñoz et al., 2004; North \& Pfefferbaum, 2002), which may be vulnerable to social desirability biases. Being upset or having "substantial stress" does not mean having a clinical disorder (Wessely, 2004), but rather having a normal reaction to an abnormal situation. Therefore, studies trying to identify subthreshold levels of traumatic responses, such as the studies of Schuster et al. (2001) or of Stein et al., (2004) based on such simple definitions of stress (e.g., "substantial stress"), may induce public alarm and confusion (Shalev, 2004; Southwick \& Charney, 2004) ${ }^{4}$.

A second measurement strategy has been the use of symptom questionnaires and cut-off scores to screen for the presence of a probable mental disorder. One of the most frequently used questionnaires has been the Posttraumatic Stress Disorder Checklist-Civilian (PCL-C; Weathers, Litz, Herman, Huska, \& Keane, 1993), a self-report instrument covering the 17 symptoms included in the definition of PTSD as currently described in the DSM-IV (1994). In terms of probable PTSD diagnoses based on the PCL-C scores, Schlenger et al. (2002) found that among their nationally representative sample of 2,273 adults, interviewed 1-2 months after S11, the overall rates of probable PTSD using the cut-off score of 50 were $11.2 \%$ in New York City, $2.7 \%$ in Washington, DC, $3.6 \%$ in major metropolitan areas, and $4 \%$ in the rest of the country. However, using a cut-off score of 40 on the same instrument, Blanchard et al. (2004) have published that the prevalence of probable PTSD for their university samples from Albany, Augusta, and North Dakota were, respectively, 11.3, 7.4, and $3.4 \%$. Unfortunately, there is no agreement on the best cut-off strategies and different results may be related to this important diagnostic decision.

Finally, a third measurement strategy is to use full diagnostic criteria to verify the presence of mental disorders (typically PTSD or ASD). In this case, a diagnosis of PTSD, for example, must include not only symptoms (Criteria B, C, and D according to the DSM-IV [1994] criteria -see Table 2) but also other requirements (e.g., Criterion F: social impairment in daily activities). The studies of the groups of Galea, et al. (2002) in the US and Miguel-Tobal et al. (2004) in Spain are good examples of this diagnostic approach. By using structured telephone interviews related to DSM-IV (1994) criteria, in a sample of Manhattan citizens, it was found that in the 5-9 weeks after S11, only $7.5 \%$ of those who had experienced direct exposure presented a probable PTSD condition, and among those who were not directly exposed, only $4.2 \%$ presented PTSD. In any case, the prevalence rate of PTSD in New York, as a whole, was of $7.5 \%$, a figure that, although it is twice as high as the one found in the American population before S11 (i.e., 3.6\%; Kessler, Sonnega, Bromet, Hughes, \& Nelson, 1995).), it does not seem extraordinarily high, given the magnitude of the event.

In view of the disparities of results among different studies which have used different instruments and/or measurement strategies (see Table 1), we designed this study to test to what extent the use of different cut-off scores in the PCL-C, all of

3 The study of Silver et al. (2002) only assessed symptoms belonging to the ASD category of the DSM-IV but not the rest of the diagnostic criteria; therefore, it cannot be clearly stated whether or not they were probable ASD cases.

4 Similar variations in results have been found when researchers have studied initial psychological reactions with the controversial category of Acute Stress Disorder (ASD)—see Vázquez (2005). This new category was first introduced in the DSM-IV (APA, 1994) — see a systematic critical review by Marshall, Spitzer and Liebowitz, 1999-to cover the measurement of psychological reactions to traumatic events within the first 30 days after a traumatic event. 


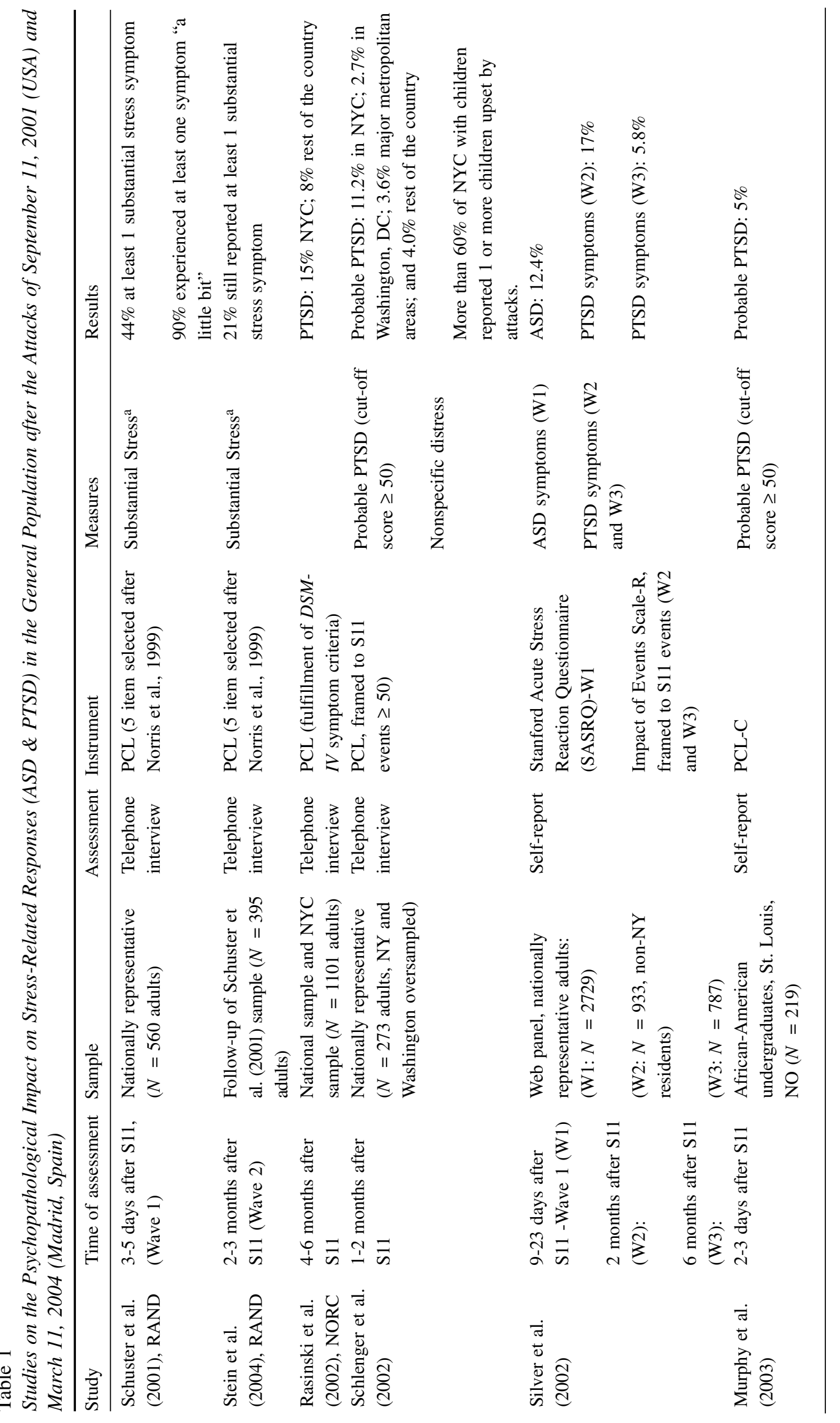




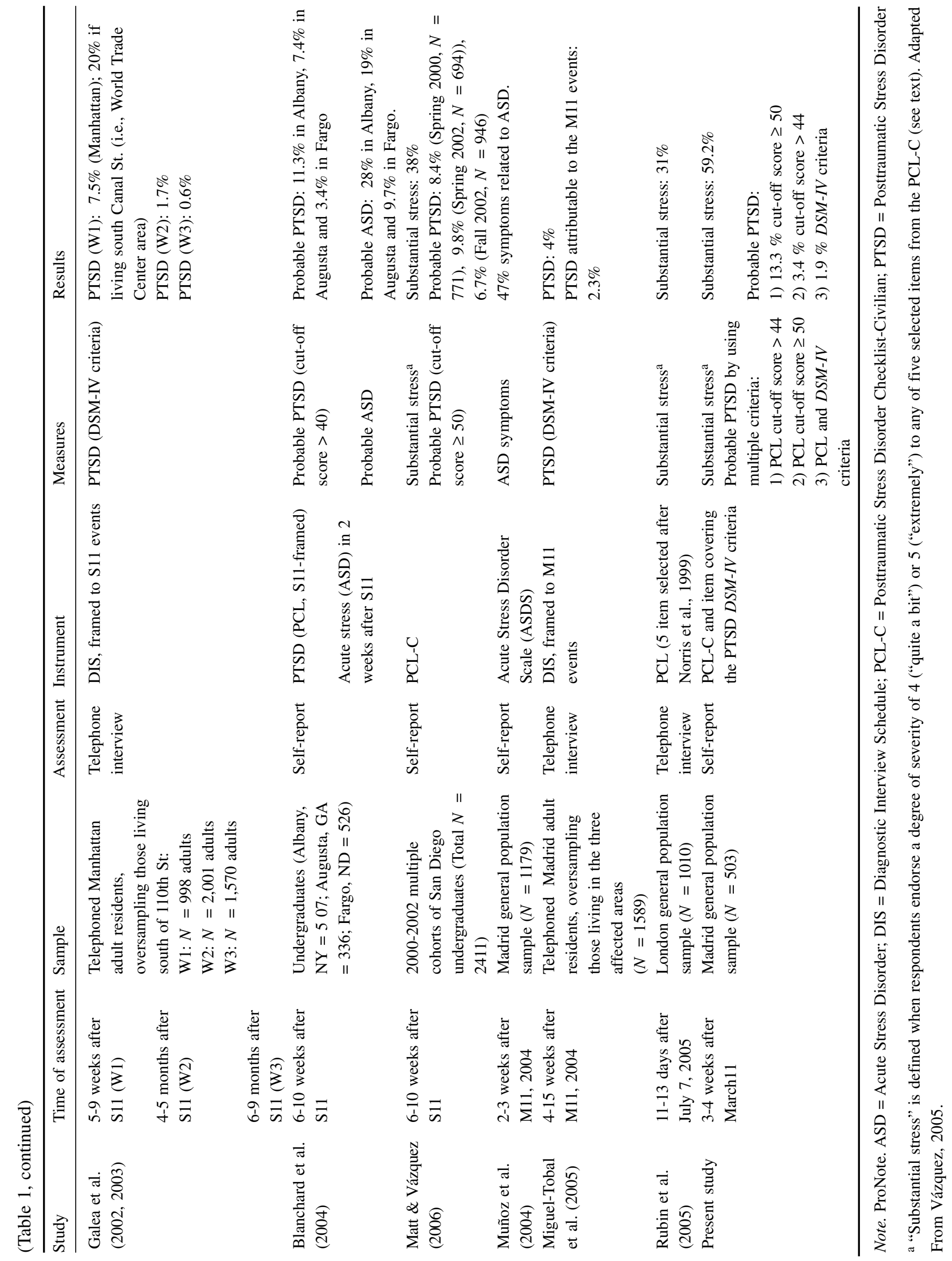


Table 2

Outline of the DSM-IV-TR (APA, 2000) Diagnostic Criteria for PTSD

Posttraumatic Stress Disorder (PTSD)

Criterion A1. Exposed to a traumatic event that involved physical threat and,

Criterion A2. Subjective reactions of fear, helplessness, or horror

Criterion B. Reexperiencing the event (1 out of 5 symptoms):

1. Intrusive recollections

2. Recurrent, distressing dreams

3. Acting or feeling as if the event were recurring

4. Distress at exposure

5. Physiological reactivity on exposure

Criterion C. Persistent avoidance (3 out of 7):

1. Efforts to avoid thoughts, feelings, or conversations associated with the trauma

2. Efforts to avoid activities, places, or people that arouse recollections of the trauma

3. Inability to recall important aspects of the trauma

4. Diminished interest to participate in significant activities

5. Feelings of detachment from others

6. Restricted range of affect

7. Sense of foreshortened future

Criterion D. Hyperarousal (1 out of 5):

1. Insomnia.

2. Irritability or outbursts of anger

3. Difficulty concentrating

4. Hypervigilance.

5. Exaggerated startle response

Criterion F: Significant distress or social impairment

them published in the literature (see Ruggiero, Del Ben, Scotti, \& Rabalais, 2003), might significantly affect the estimates of probable cases within a sample of the general population of Madrid assessed 2-3 weeks after the terrorist attacks. A second goal of our study was to explore the impact of assessing additional diagnostic criteria, in addition to trauma-related symptoms, to estimate probable cases of PTSD. In fact, one of the main diagnostic limitations of the studies based on symptom checklists is that they typically do not cover other required criteria to diagnose PTSD (see North \& Pfefferbaum, 2002). These symptom-based instruments adequately cover Criteria B, C, and D of the DSM-IV (1994) definition of PTSD (i.e., symptoms), but not Criterion A2 (i.e., initial subjective response) $)^{5}$ and, more important, Criterion $\mathrm{F}$ (i.e., significant problems in the daily functioning)—see Table 2. This latter criterion is extraordinarily important, as the inclusion of functioning difficulties may reduce epidemiological figures of mental disorders in the general population up to one half (Narrow, Rae, Robin, \& Regier, 2002). Thus, we designed the study to include an assessment of Criteria $\mathrm{A}$ and $\mathrm{F}$ in addition to the PTSD symptoms, which are well covered by the PCLC. Our overall hypothesis was that the impact of the traumatic event in the general population, according to what was already known after the 11S US attacks, would be rather limited (see Vázquez, 2005) and, furthermore, that impact would depend largely on the criteria used to define "cases." Finally, we explored the role of exposure risk factors on both post-traumatic symptoms and probable PTSD by using different cut-off scores.

\section{Method}

\section{Participants}

One week after the M11, 2004, attack, a class of university psychology students in Madrid was asked to participate in a study on the effects of terrorist attacks. Students completed a questionnaire and recruited two other adult persons, aged 18 and older, who were in Madrid on March 11, 2004. The final total sample consisted of 503

\footnotetext{
5 Although initial response is restricted to Criterion A2, we assume that all participants met Criterion A1 as the nature of the M11 traumatic experience literally fits the definition of trauma described in the DSM-IV Criterion A1: "the person experienced, witnessed, or was confronted with an event or events that involved actual or threatened death or serious injury, or a threat to the physical integrity of self or others."
} 
respondents (67\% female) whose average age was 31.4 years: 194 university students and 309 persons from the general population ${ }^{6}$. All participants returned the questionnaires 1825 days after the terrorist event.

\section{Measures}

Initial reactions (Criterion A2, DSM-IV). To explore whether different initial reactions could affect the development of subsequent trauma-related symptoms, we used a 10-point rating scale, ranging from 0 (not at all) to 10 (extreme intensity), on which participants rated the intensity of "fear," "feelings of horror," and "helplessness" in the first hours after the trauma occurred. In addition to these three symptoms that make up DSM-IV (1994) and DSM-IV-TR (2000) Criterion A2 for PTSD, we also examined other initial reactions that may play an important role in the development of PTSD (e.g., fear that someone known to the person could have been affected, bodily symptoms such as sweating, trembling, feeling upset and angry_Bracha et al., 2004; Brewin, 2003). Participants also rated the duration in hours of these emotional reactions in the 24-hour period following the attacks.

Post-traumatic symptoms (Criteria B, C and D, DSM$I V)$. The Posttraumatic Stress Disorder Checklist-Civilian (PCL-C; Weathers et al., 1993) is a 17-item self-report measure of posttraumatic stress reactions that adequately covers the set of symptoms associated with PTSD as defined in the DSM-IV (1994) and DSM-IV-TR (2000)Criteria B (Reexperiencing), C (Avoidance), and D (Hyperarousal). Items are scored on a scale anchored from 1 (not at all) to 5 (extremely). The possible range of scores is 17-85. Test-retest reliability at 2-3 days has been reported at .96 (Weathers et al., 1993), and the overall diagnostic efficiency has been found to be acceptably high at .90 (Blanchard, Jones-Alexander, Buckley, \& Forneris, 1996). In our study, the scale was shown to be highly consistent (Cronbach's $\alpha=.89$ ).

Similar to the majority of studies related to the S11 events (e.g., Blanchard et al., 2004), the PCL-C was explicitly framed with respect to the M11 terrorist attacks (i.e., whereas in the standard instructions, participants are asked to indicate how much they have been bothered by those symptoms in the last month, in our instructions, participants were asked to inform on their symptoms since the day of the attacks). The scores on the PCL-C were used in three different ways:

1. PCL-C total scores. PCL total score and the three subscales which correspond to the DSM-IV (1994) Criteria $\mathrm{B}, \mathrm{C}$, and $\mathrm{D}$ respectively

2. Substantial stress level (SL). To compare our data with those from previous studies (Matt \& Vazquez, 2006; Rubin et al., 2005; Schuster et al., 2001; Stein et al., 2004), SL was defined as a response of 4 or 5 to one or more than five PCL-C items.

3. Probable PTSD diagnosis. To determine rates of psychological distress related to PTSD, three strategies differing in restrictiveness were compared:

3.1. Low threshold criterion (PCL total score $>44$ ). This criterion, which minimizes the number of false negative cases, has been repeatedly used in epidemiological studies related to the S11 attacks (Blanchard et al., 2004).

3.2. High threshold criterion ( $\mathrm{PCL} \geq 50$ ). A cut-off score of 50 or above has also been used in national studies on the effects of the S11 attacks (Schlenger et al., 2002). Yet, to reduce false positive cases (see Ruggiero et al., 2003), items were computed only when reaching a severity threshold (i.e., a score of 4 or 5: quite a bit or extremely, respectively) ${ }^{7}$.

3.3. Clinical criteria based on psychometric measures. We established a $D S M-I V$-based strategy consisting of checking whether a given criterion was fulfilled. Criterion A2 was considered met when a participant responded with a score of 8 or above to any of the reactions described in DSM-IV (1994; i.e., horror, fear, or helplessness) ${ }^{8}$. Criterion $\mathrm{B}, \mathrm{C}$, and D were met whenever a participant met the number of symptoms required respectively for each criterion (one out of five reexperiencing symptoms, three out of seven avoidance symptoms, and two out of five hyperarousal symptoms). Presence of a symptom was defined by a score of 4 or 5 on each corresponding PCL-C item. Criterion F was met if a participant scored 8 or above on the Global functioning item ${ }^{9}$.

Global functioning (Criterion F, DSM-IV). Problems in "global functioning" (Criterion F for PTSD, according to $D S M-I V, 1994$, and DSM-IV-TR, 2000) assessed the extent to which the M11 events were still affecting participants' daily activities - at work, at home, or in interpersonal relations-on a scale of 1 (not affected in daily activities) to 10 (extremely affected in daily activities).

\footnotetext{
6 We conducted a series of analyses comparing PCL-C scores in both samples, finding no significant differences in any PCL scale. Thus, both samples were combined in this report.

7 A score of 3 or above is required for items 1,2, 9, 10, 12, and 15, whereas a score of 4 or above is required for the rest of the items.

8 A score of 8 or above in a 1-10 scale would be equivalent to a score of 4 or above in the 1-5 scale of the PCL-C.

9 Criterion E (duration of symptom more than 1 month) was not directly assessed as this study was conducted between the third and fourth week after the attacks. Thus, the responses covered a 3-4 week period, as the PCL instructions asked subjects to rate the severity of symptoms since March 11.
} 
Table 3

Risk Factors, Levels of Exposure and Levels of Post-Traumatic Stress Symptoms and Probable PTSD (Based on PCL Scores)

\begin{tabular}{|c|c|c|c|c|c|c|c|}
\hline \multirow[b]{2}{*}{$\begin{array}{l}\text { Risk factors and levels } \\
\text { of exposure }\end{array}$} & \multicolumn{4}{|c|}{ PCL scores $M$ and $(S D)$} & \multicolumn{3}{|c|}{ Probable PTSD (\%) } \\
\hline & Total Score & Reexperiencing & Avoidance & Hyperarousal & $\begin{array}{c}\text { PCL > } 44 \\
\text { (Including } \\
\text { all items) }\end{array}$ & $\begin{array}{l}\text { PCL > 50 } \\
(\text { Only items } \\
\text { scoring > 4) }\end{array}$ & $\begin{array}{c}D S M-I V \text { criteria } \\
\text { (PCL and } \\
\text { additional items) }\end{array}$ \\
\hline Overall sample $(N=503)$ & $31.9(12.9)$ & $10.9(3.6)$ & $10.9(3.8)$ & $10.1(4.3)$ & 13.3 & 3.4 & 1.9 \\
\hline \multicolumn{8}{|l|}{ Gender } \\
\hline Female $(N=339)$ & $32.8(10.5)^{* *}$ & $11.3(3.7)^{* *}$ & $11.1(3.9)$ & $10.5(4.4)^{* *}$ & 14.4 & 3.8 & 2.1 \\
\hline Male $(N=148)$ & $29.6(9.4)$ & $9.9(3.3)$ & $9.9(3.3)$ & $9.2(3.9)$ & 11.3 & 2.0 & 1.4 \\
\hline \multicolumn{8}{|l|}{ Location of residence $* * *$} \\
\hline Proximity $1-(N=54)$ & $37.6(12.9)$ & $12.8(4.1)$ & $12.8(4.8)$ & $12.0(5.3)$ & 29.6 & 11.1 & 5.8 \\
\hline Proximity $2-(N=40)$ & $32.6(8.7)$ & $11.3(3.8)$ & $10.6(2.8)$ & $10.0(3.8)$ & 12.5 & 0.0 & 0.0 \\
\hline Proximity $3-(N=246)$ & $31.3(9.3)$ & $10.5(3.2)$ & $10.7(3.5)$ & $10.0(3.9)$ & 10.6 & 1.6 & 1.2 \\
\hline Proximity $4-(N=159)$ & $30.9(10.8)$ & $10.8(3.7)$ & $10.6(4.1)$ & $9.5(4.2)$ & 12.6 & 4.4 & 2.5 \\
\hline \multicolumn{8}{|l|}{ Personally exposed } \\
\hline Yes $(N=20)$ & $41.1(13.4)^{* * *}$ & $14.2(4.2)^{* * *}$ & $13.5(5.4)^{* *}$ & $13.3(4.9)^{* * *}$ & $30.0^{*}$ & $15.0 * *$ & $5.0^{*}$ \\
\hline No $(N=483)$ & $31.5(9.9)$ & $10.8(3.5)$ & $10.8(3.8)$ & $9.9(4.2)$ & 12.6 & 2.9 & 1.9 \\
\hline \multicolumn{8}{|l|}{ Perception of life at risk } \\
\hline Yes $(N=147)$ & $36.9(11.6)^{* * *}$ & $12.4(3.8)^{* * *}$ & $12.4(4.5)^{* * *}$ & $12.1(4.8)^{* * *}$ & $25.2 * * *$ & $7.5^{* *}$ & $4.2 *$ \\
\hline No $(N=338)$ & $30.0(9.0)$ & $10.4(3.3)$ & $10.3(3.4)$ & $9.4(3.7)$ & 8.9 & 1.8 & 1.2 \\
\hline \multirow{2}{*}{\multicolumn{8}{|c|}{$\begin{array}{l}\text { Knowing someone } \\
\text { directly affected }\end{array}$}} \\
\hline & & & & & & & \\
\hline Yes $(N=218)$ & $33.8(11.4)^{* * *}$ & $11.3(3.8)^{*}$ & $11.4(4.4)^{* *}$ & $11.1(4.7)^{* * *}$ & $17.9 * *$ & $5.9 * *$ & $3.7^{*}$ \\
\hline No $(N=285)$ & $30.5(9.1)$ & $10.6(3.4)$ & $10.5(3.4)$ & $9.4(3.8)$ & 9.8 & 1.4 & 0.7 \\
\hline \multicolumn{8}{|l|}{ User of affected train lines } \\
\hline Yes $(N=73)$ & $35.8(11.8)^{* * *}$ & $12.1(4.0)^{*}$ & $11.9(4.3) * *$ & $11.8(4.8)^{* * *}$ & $24.7 * *$ & 6.8 & $5.6^{*}$ \\
\hline No $(N=429)$ & $31.2(9.9)$ & $10.7(3.5)$ & $10.7(3.8)$ & $9.8(4.1)$ & 11.4 & 2.8 & 1.4 \\
\hline
\end{tabular}

Note. Proximity of residence to where the bombs exploded $(1=$ same neighborhood or very close; $2=$ same area, not neighborhood; 3 = Madrid metropolitan area; 4 = Madrid, outside metropolitan area).

$* p<.05 . * * p<.01 . * * * p<.001$.

Exposure to the events. To explore the role of exposure in the reactions to the terrorist attacks, we included questions used by Galea et al. (2002), Schuster et al. (2001), and items recommended by the Office of Behavioral and Social Sciences Research of the National Institutes of Health (2002) to assess the impact of the S11 attack. The questionnaire asked respondents to report whether they had directly witnessed the attacks, lived close to the scenarios where the attacks happened, used to take the train lines that were attacked, or had friends or relatives who were wounded or killed during the attacks. We also included retrospective self-report measures of media exposure (newspapers, TV, radio or Internet) during the week of the attacks.
Results

\section{Posttraumatic Stress Responses (PCL-Total Scores)}

The mean PCL-C total score was $31.9(S D=12.9)$ see Table 3. An analysis of sex differences showed that women had a more intense reaction than men as reflected in higher scores on the PCL-C total, $t(487)=3.15, p<.002$; symptoms of reexperiencing, $t(487)=3.85, p<.001$; and hyperarousal, $t(487)=2.97, p<.003$. Yet, there were no significant sex differences on avoidance total score, $t(487)$ $=1.16, p<.11$. 


\section{Substantial Stress}

Overall, a high percentage of respondents (59.2\%) manifested a "substantial stress level" as defined by Schuster et al. (2001). Women were more likely than men $(61.7 \%$ vs. $52.0 \%)$ to report substantial stress levels, $\chi^{2}(1, N=488)=4.04, p<.04$ (Figure 1 ). The most prevalent symptom (for men and women) was "feeling very upset when something reminded you of what happened" ( $94 \%$ of the sample), and the least prevalent was "trouble remembering important parts of the event" (14.1\%).

An interesting result emerged from our study when the overall magnitude of the severity of the PCL-C items was analyzed (Figure 2). The mean magnitude of the PCL-C symptoms $(M=1.88)$ did not even reach the severity threshold of 2 (i.e., "a little bit"), which casts some doubts about catastrophic discourses on the implications of this disaster for general population. As can be seen in Figure 2, almost identical results have been found in different samples after the S11 attacks.

\section{Probable PTSD Diagnosis}

Table 4 shows the data on probable PTSD diagnosis based on PCL scores using different strategies. As can be seen in the table, rates of PTSD changed significantly depending on which criterion is used. For the entire sample, using the cut-off score $>44$ proposed by Blanchard et al. (1996), 13.3\% of the sample received a probable PTSD disorder, whereas the prevalence rate dropped to just 3.4\% when the stricter criterion suggested by Ruggiero et al. (2003) was used instead. Thus, applying different criteria commonly used in studies with the PCL-C may result in a fourfold difference between probable diagnostic rates.

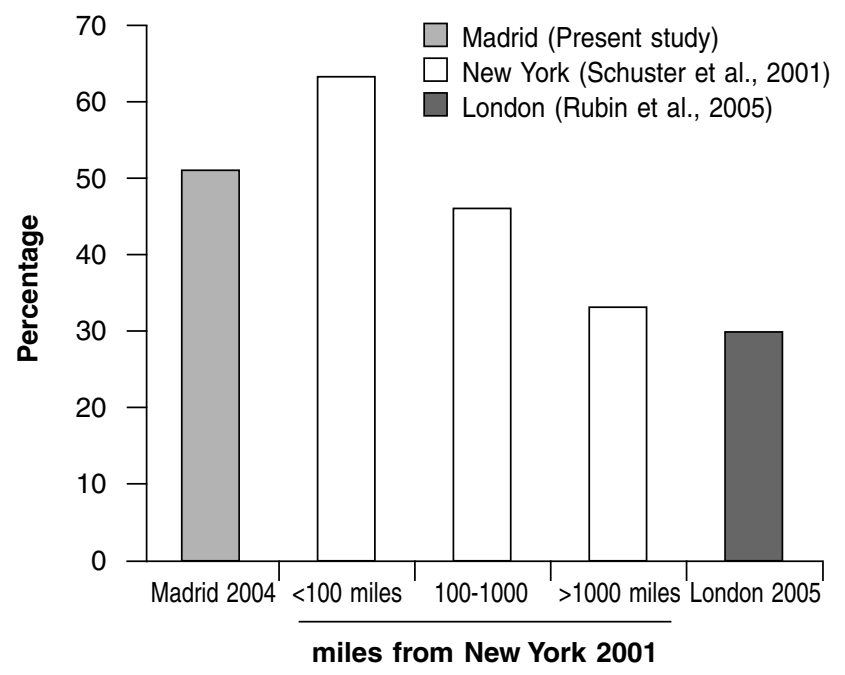

Figure 1. Prevalence of "Substantial Stress" Reactions (as Defined by Schuster et al., 2001) among Different Samples from the General Population in the US (Living at 3 Different Locations at Different Distances From Manhattan), Madrid, and London after their Respective Terrorist Attacks
Finally, according to the approach modeled after DSMIV (1994) criteria, only $1.9 \%$ of the total sample received a probable diagnosis of PTSD-one seventh of the PCL > 44 strategy. Further investigation showed that sex differences were significant only for a subset of symptoms. More specifically, a significantly higher proportion of women than men showed a strong initial emotional reaction to the event (Criterion A), $\chi^{2}(1, N=481)=48.9, p<.0001$; and more symptoms related to reexperiencing (Criterion B), $\chi^{2}(1, N=486)=4.43, p<.03$. Considering all criteria together, women and men showed similar levels $(2.1 \%$ vs. $1.4 \%)$ of probable PTSD, $\chi^{2}(1, N=485)=0.27, p<.60$. Items related to avoidance behaviors (Criterion $\mathrm{D}$ ) and global functioning (Criterion F) - see Table 4-were much less frequent than items related to reexperiencing and hyperarousal.

\section{Initial Reactions and Posttraumatic Response}

With the exception of bodily symptoms $(M=3.2 \pm 3.2)$, the average initial reaction was rather intense, ranging from $M=6.0 \pm 3.1$ (fear) to $M=7.5 \pm 2.6$ (helplessness). This included the three symptoms of the DSM-IV (1994) definition of Criterion A as well as other reactions (e.g., feelings of anger, "fear that someone I know could be affected," and feeling "upset" about what had happened). The average duration of the initial reaction was $1.9 \pm 1.0$ hours and, in general, the intensity of these emotional reactions was significantly correlated with all the PCL-C scores (correlations between emotional reactions and PCL$\mathrm{C}$ total score ranged from $r=.54, p<.001$ for bodily symptoms to $r=.32, p<.001$ for anger).

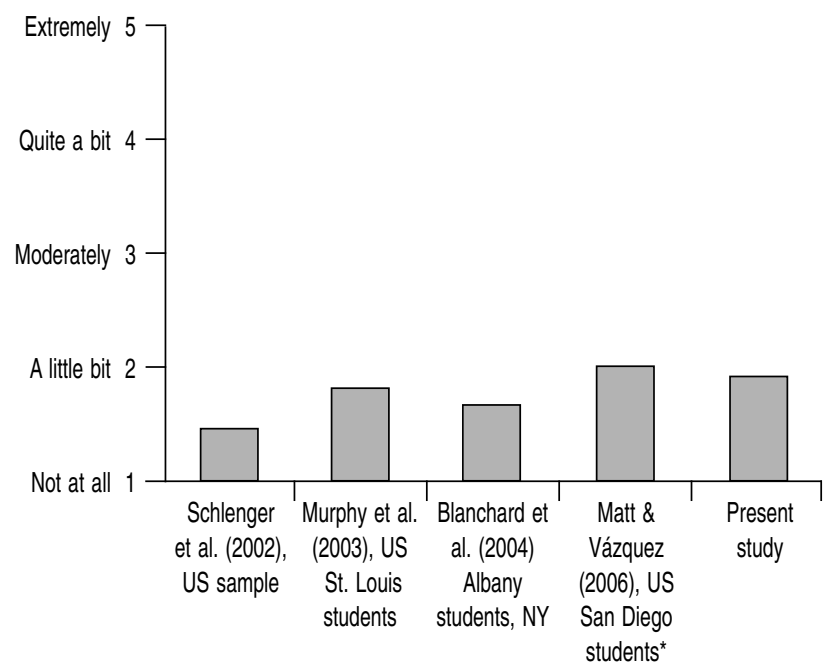

*Only 5 items from the PCL-C scale were used (see Schuster et al., 2001).

Figure 2. Mean Severity (From $1=$ Not At All to $5=$ Extremely) of the PTSD Symptoms Assessed by the PCL-C Scale in Different Samples of the General Population within the Days or Weeks Immediately after S11-2001 and M11-2004 
Table 4

Percentage of Participants Meeting Levels of Substantial Stress (SL) and Probable PTSD According to Different Diagnostic Strategies

$\begin{array}{lll}\text { Total sample } \quad \text { Male } & \text { Female } & \text { PCL definition: } \\ & & D S M-I V \text {-based } \\ & & \\ & \end{array}$

definition ratio

\begin{tabular}{|c|c|c|c|c|}
\hline \multicolumn{5}{|l|}{ Psychometric criteria (PCL scores) } \\
\hline Substantial Stress (Selected PCL-C items scored 4 or 5) & 59.2 & 52.0 & $61.7 *$ & \\
\hline PTSD using PCL $>44$ & 13.3 & 11.3 & 14.4 & $7: 1$ \\
\hline PTSD using PCL $>50$ and items scoring $>4$ & 3.4 & 2.0 & 3.8 & $1.7: 1$ \\
\hline \multicolumn{5}{|l|}{ DSM-IV-based clinical criteria } \\
\hline All $D S M-I V$ criteria & 1.9 & 1.4 & 2.1 & $1: 1$ \\
\hline Criterion A2 (Initial reaction to the event) & 78.2 & 58.2 & $86.9 * *$ & \\
\hline Criterion B (Reexperiencing: 1/5) & 56.2 & 49.0 & $59.3 *$ & \\
\hline Criterion C (Avoidance: $3 / 7$ ) & 3.8 & 2.8 & 4.2 & \\
\hline Criterion D (Hyperarousal: 2/5) & 19.1 & 15.8 & 20.5 & \\
\hline Criterion F (Functioning) & 6.3 & 5.6 & 6.6 & \\
\hline Criteria B + C + D (cluster of symptoms) & 3.2 & 2.0 & 3.6 & \\
\hline Criteria $\mathrm{A} 2+\mathrm{B}+\mathrm{C}+\mathrm{D}$ (Initial reaction and symptoms) & 2.0 & 1.4 & 2.1 & \\
\hline
\end{tabular}

$* p<0.05$. $* * p<0.01$.

\section{Risk Factors and Stress Reactions}

To investigate the effects of place of residence on posttraumatic stress-related symptoms, we conducted a series of univariate ANOVAs with proximity of residence to the places of the attacks as between-subject factor and PCL scores as response variables. The univariate tests revealed a statistically significant main effect on the total PCL-C, $F(3,495)=6.5, p$ $<.001, \eta^{2}=.04$; reexperiencing, $F(3,494)=6.1, p<.001, \eta^{2}$ $=.04$; avoidance, $F(3,495)=4.8, p<.001, \eta^{2}=.03$; and hyperarousal, $F(3,495)=5.2, p<.001, \eta^{2}=.03$. Post-hoc MSD tests revealed a similar pattern in all dependent variables (see Table 3), showing that people living "very close to or in the same neighborhood" where the bombs exploded had more symptoms than people living in other places.

A series of $t$-tests for independent samples was also conducted to explore other risk factors (see Figure 2). The results revealed higher significant total PCL-C scores in participants who were close to where the bombs exploded (i.e., "personally exposed"), $t(501)=4.1, p<.001$; who perceived their life at risk, $t(483)=7.1, p<.001$; were physically injured, $t(501)=4.1, p<.001$; personally knew someone affected by the explosions, $t(501)=3.6, p<.001$; or who were users of the train lines where the bombs exploded, $t(501)=3.6, p<.001$. An identical pattern of results was found on the three subscales of the PCL-C (reexperiencing, avoidance, and hyperarousal)—see Figure 2. Yet, there was no significant difference for being a user of trains in general.

The analysis of participants' global functioning revealed that, on a $0-10$ scale, the average was not high $(M=3.7 \pm 2.2)$. Sex differences revealed that, compared to men, women had more difficulties in daily activities, $t(475)=4.27, p<.001$ ( $M=3.84$ vs. 3.32$)$ in relation to the M11 attacks.

As was also the case with raw PCL-C scores, further analyses revealed that risk factors were significantly associated with probable diagnoses of PTSD. In the case of the PCL > 44 criterion, living closer to the areas affected, $\chi^{2}(3, N=499)$ $=14.05, p<.003$; having been directly exposed, $\chi^{2}(1, N=$ $503)=5.02, p<.02$; having perceived life at risk, $\chi^{2}(1, N=$ $485)=22.84, p<.001$; having been physically injured, $\chi^{2}(1$, $N=485)=11.81, p<.001$; knowing someone directly affected, $\chi^{2}(1, N=502)=6.96, p<.008$; and being a user of the attacked train lines, $\chi^{2}(1, N=502)=9.49, p<.002$; were all significantly associated with the likelihood of having a PTSD disorder, as defined by these criteria. Similar results were obtained with the other two criteria. Although PCL-C scores were significantly higher in women than in men, sex analyses of categorical diagnoses revealed no significant association between sex and probable PTSD, using either the PCL $>44-\chi^{2}(1, N=489)=1.63, p<.20-$, the PCL $>50-\chi^{2}(1, N=489)=1.04, p<.31-$, or the DSM-IV-TR (2000) criteria- $\chi^{2}(1, N=485)=0.27, p<.60$.

\section{Media exposure}

Media coverage of the M11 attacks was intense and extensive and attracted a large audience. Similar to S11 USA audiences, where Schuster et al. (2001) found that the average American adult watched approximately 8 hours of TV coverage on that day, participants in the Madrid study watched TV news for an average of 5.1 hours/day during the first three days. Furthermore, during the first week, they 
listened to radio news an average of 1.8 hours/day, read newspapers an average of 4.1 hours/day, and browsed Internet news an average of 1.4 hours/day. More specifically, participants believed that their initial reactions (Criterion A) were highly affected by the impact of the TV images they watched within the first hours after the attacks (33.6\% said that TV images affected them "very much," $39.0 \%$ "a lot," $22.5 \%$ "to some extent," and 4.2\% "not at all"). Participants also acknowledged that exposure to news, in general, affected their mood negatively ("not at all" $=3.0 \%$; "to some extent" $=31.8 \%$; "quite a bit" $=37.8 \%$; "quite a lot" $=16.9 \%$; "very much" $=9.9 \%$ ) although, in a similar proportion, respondents also recognized that exposure to news helped them to better understand what happened ("not at all" $=7.2 \%$; "to some extent" $=16.9 \%$; "quite a bit" $=32.4 \%$; "quite a lot" = $31.8 \%$; "very much" $=11.3 \%$ ). Zero-order correlations between the amount of media exposure and the total PCLscore were significant for the average daily TV watching during the first 3 days $(r=.14, p<.01)$ and during the first week $(r=.14, p<.05)$ as well as for the daily radio listening $(r=.15, p<.01)$. Correlations between PCL symptoms and reading newspapers and watching Internet news did not reach statistical significance.

\section{Discussion}

The sample of citizens of Madrid experienced patterns and levels of emotional distress in the first days following the terrorist attacks of M11 that were similar to those reported in the general USA population after the S11 attacks. The level of "substantial stress" in our sample (59.2\%) was very similar to that found by Schuster et al. (2001)-61\% - in their subsample of US citizens living closer to the World Trade Center but higher than the percentage of Londoners affected by the July 2005 attacks (31\%). Rubin et al. (2005) have argued that differences between the impact of the attacks on the US and London samples may be due, among other causes, to differences in the magnitude of the events, the limited TV coverage of the London attacks, and even the previous experience of the British people with IRA terrorist attacks. However, as we said before, although the concept of substantial stress may be clinically "unsubstantial," these differences among samples from different places still remain unexplained.

Based on the symptoms reported in a questionnaire, a preliminary study conducted by Muñoz et al. (2004) between 18-24 March 2004 showed that $47 \%$ of a Madrid general population sample $(N=1,179)$ had an acute stress reaction in relation to the M11 attacks, as measured by the Acute Stress Disorder Scale (ASDS; Bryant \& Harvey, 2000). Yet, although initial psychological reactions to the M11 events were in some cases dramatic and, as our data showed, intense initial reactions (Criterion A2) were very common, there is also mounting evidence that these acute responses are limited in scope and quickly return to normal levels (Marshall, Spitzer, \& Liebowitz
1999; McNally, Bryant, \& Ehlers, 2003; Muñoz et al., 2004). Silver et al., (2002) found that $17 \%$ of their nationwide sample of adults residing outside New York City reported posttraumatic stress symptoms 2 months after S11, but only 6\% reported symptoms at 6 months. A similar pattern has been found for PTSD diagnoses in the general population. Galea et al. (2003) analyzed the prevalence of PTSD in the general population of New York City in three consecutive telephone surveys conducted one month, four months, and six months after S11, 2001 showing that prevalence rates declined from $7.5 \%$ to $0.6 \%$ six months after the incident. Therefore, the transitory nature of traumatic stress responses found in the majority of the general population suggests that acute emotional distress should not be mistaken for direct indicators of later PTSD. As McNally et al. (2003) and Silver et al. (2002) have argued, high initial emotional responses may be part of the natural recovery, improving without the assistance of professional help in the presence of supportive environments. Thus, a pattern of acute stress reactions after trauma in the hours, days, or even weeks after a traumatic event occurs should be cautiously interpreted (Kilpatrick et al., 1998; North \& Pfefferbaum, 2002). In fact, there is a strong debate about the clinical and epidemiological significance of this type of findings. Studies attempting to identify subthreshold levels of traumatic responses (e.g., Muñoz et al., 2004; Stein et al., 2004) based on simple definitions of stress may induce public alarm and confusion (Shalev, 2004; Southwick \& Charney, 2004). Immediately after the S11 attacks, health policymakers predicted a major mental health crisis among New York citizens (Herman, Felton, \& Susser, 2002; Stephenson, 2001). A similar scenario was predicted in Madrid by governmental authorities (Sampedro, 2004). Yet, the epidemiological studies conducted in New York (Galea et al., 2002) and in other US cities (Schlenger et al., 2002) had already shown that prevalence rates of PTSD disorders in the general population were not disproportionate relative to pre-S11 attack rates and dropped significantly during the first few months after the tragedy. Consistent with these findings, the data from large managed behavioral health organizations had similarly shown a pattern of no significant increases in prescription of psychotropic medications between September 2001 and January 2002 (McCarter \& Goldman, 2002) or in the incidence of PTSD or other mental disorders in the New York Veteran Hospitals network (Boscarino, Galea, Ahern, Resnick, \& Vlahov, 2002; Rosenheck \& Fontana, 2003). Furthermore, the overall magnitude of the general population's stress reaction is quite low. Both in our study, as in previous ones (see Figure 2), the overall mean intensity of the PTSD symptoms was never above 2 on a $1-5$ scale.

In the present study, we used three different strategies to diagnose PTSD based on the PCL-C. Using two different scoring methods and a clinical approach, we observed the prevalence rate to drop from $13.3 \%$ to $1.9 \%$. In fact, using structured interviews and following DSM-IV-TR (2000) criteria, Miguel-Tobal et al. (2004) estimated that only $4 \%$ of their 
Madrid sample fulfilled PTSD criteria, and 2.3\% had a probable PTSD which was attributable to the M11 terrorist attacks.

Researchers and policy makers should pay attention to these variations in probable prevalence rates, which depend upon the use of different diagnostic and threshold criteria (North \& Pfefferbaum, 2002), for an adequate and sensible planning of health services (Southwick \& Charney, 2004). Unfortunately, there is no sound epidemiological study, as far as we know, that had been conducted in the Madrid general population on the prevalence of PTSD before March 11, 2004. Yet, it is interesting to note that, in an ongoing project on the prevalence of DSM-IV-TR (2000) mental disorders in six European countries (ESEMeD/MHEDEA, 2004)—Belgium, France, Germany, Italy, the Netherlands, and Spain (total $N$ $=21,425)$ - PTSD 12-month and lifetime-prevalence rates are noticeably smaller $(0.9 \%-1.9 \%$, respectively) than those found in comparable US studies (e.g., Kessler et al., 1995). Future studies should pay attention to the possibilities of directly comparing the figures on psychological reactions to traumatic events in different countries and cultures.

Our findings are consistent with other studies showing that physical proximity to traumatic events is an important risk factor for developing traumatic responses (Cano-Vindel et al., 2004; North, Smith, \& Spitznagel, 1994; Sprang, 1999). In the case of the S11 attacks, Schlenger et al. (2002) found that 1-2 months after S11, probable diagnosis of PTSD based on a PCL-C score of 50 or above, was much more common in the New York City metropolitan area (11.2\%) than in the rest of country $(4.0 \%)$, where the prevalence rates were within the range observed before S11 in the US general population. Using a structured telephone interview and DSM-IV (1994) criteria, Galea et al. (2002) found that 5-9 weeks after S11, the prevalence of PTSD was approximately twice as high among residents of Manhattan than the 12-month prevalence rates found in the general population-7.5\% versus $3.6 \%$ (Kessler et al., 1995). Similarly, Blanchard et al. (2004) have reported that probable PTSD based on a PCL-C cut-off score affected $11.3 \%$ of their sample of undergraduates from the University of New York at Albany, whereas the same disorder was much less likely to affect students in more distant areas of the country.

Regarding the impact of mass media exposure, the Madrid sample had a similar exposure to that found in comparable studies. The impact of this exposure is significant but almost restricted to the TV watched in the first week. Furthermore, the effect size of this finding was relatively small. In any case, although there is a public debate about the role of mass media in the development of PTSD and other traumatic responses, Ahern et al. (2002) have shown that frequent television viewing of the S11 attacks had an impact on PTSD symptoms and depression only in individuals who had a direct event experience (e.g., direct witnessing or having a friend or relative killed) but not in those who had no direct experience.

Our findings portray a response to these traumatic events that is consistent with other research, showing a dramatic surge in some PTSD symptoms immediately following S11 with little, if any, implication for psychopathology in the general population (McNally et al., 2003), and a number of significant risk factors associated both with PCL scores and categorical PTSD diagnoses. However, the pattern of results on the magnitude of the response calls for the need to be cautious about the dangers of confounding normal emotional distress with clinically significant disorders, especially when using psychometric criteria as the main source of data. The dangers of this kind of decision, from an epidemiological and public health perspective of media and population impact in terms of fear and alarm, should be seriously considered (Southwick \& Charney, 2004). Although the present study cannot be considered as a robust epidemiological research, mainly due to sampling limitations, it provides some critical hints on the limitations of methods that intend to screen for mental disorders in the population. In our opinion, epidemiological estimates of similar studies should be carefully examined, as variations in diagnostic cut-off scores and strategies may have dramatic effects on the resulting estimates. Researchers and policy makers should pay attention to these variations in probable prevalence rates, which depend upon the use of different diagnostic and threshold criteria (North \& Pfefferbaum, 2002), for an adequate and sensible planning of health services (Southwick \& Charney). It is likely that an appropriate way to provide more reliable estimates of the impact of terrorist attacks on the general population is to focus not only on symptoms (e.g., Blanchard et al., 2004; Schuster et al., 2001; Stein et al., 2004) but also on the impact on functioning (see North \& Pfefferbaum, 2002), as this could be one of the most relevant criteria for seeking help in victims of trauma (Shalev, 2004). In fact, the results of our study support the idea that two components of the formal definition of PTSD (i.e., avoidance behaviors and a deficit in psychosocial functioning) are crucial to increase or to decrease the estimations of PTSD prevalence (see also Brewin, Andrews, \& Rose, 2000). Data from simple self-report measures only covering symptoms should be viewed with caution unless the authors use cut-off scores that maximize specificity and include questions on effective psychosocial functioning. In brief, an adequate assessment should systematically include: (a) being directly physically or psychologically threatened by the event versus being only exposed to information about the event, (b) the presence of an initial emotional reaction of unbearable fear or horror, and (c) a sustained impact of the symptoms on daily functioning since the event.

The present study has also some limitations. As we have already mentioned, the snowball procedure used in our study is not an adequate method to arrive at reliable epidemiological figures of any disorder. Thus, our results should not be considered valid estimates of the prevalence of mental disorders in the Madrid population and, in fact, this was not our goal in designing the study. Furthermore, although the use of self-report measures is common in this type of studies, it would be preferable to use structured interviews to provide 
diagnoses of trauma-related psychological disorders. Finally, although our results clearly suggest that the assessment of psychosocial dysfunctions related to the trauma reduces the rates of diagnosed PTSD, such assessments should be conducted using more sophisticated measures in future studies.

As a final point, we would like to stress that, in the case of the Madrid attack, a number of unique political circumstances created a complex social scenario where positive and negative emotions were particularly mixed during the first days after the tragedy. In fact, the Spanish general elections took place just 3 days after these attacks and were marked by an intense emotional climate. One of the next steps of our group will be to analyze the role of these negative and positive emotions (Fredrickson, Tugade, Waugh, \& Larkin, 2003; Pérez-Sales, Cervellón, Vázquez, Vidales, \& Gaborit, 2005; Vázquez, Cervellón, Pérez Sales, Vidales, \& Gaborit, 2005) in the development and/or maintenance of post-traumatic symptoms taking advantage of that extraordinary occasion.

\section{References}

Ahern, J., Galea, S., Resnick, H., Kilpatrick, D., Bucuvalas, M., Gold, J., \& Vlahov, D. (2002). Television images and psychological symptoms after the September 11 terrorist attacks. Psychiatry, 65, 289-300.

American Psychiatric Association (1994). Diagnostic and statistical manual of mental disorders (4 ${ }^{\text {th }} \mathrm{ed}$.). Washington, DC: Author.

American Psychiatric Association (2000). Diagnostic and statistical manual of mental disorders ( $4^{\text {th }}$ ed., text revision). Washington, DC: Author.

Blanchard, E.B., Hickling, E.J., Barton, K.A., Taylor, A.E., Loos, W.R., \& Jones-Alexander, J. (1996). One-year prospective follow-up of motor vehicle accident victims. Behaviour Research and Therapy, 34, 775-786.

Blanchard, E.B., Jones Alexander, J., Buckley, T.C., \& Forneris, C.A. (1996). Psychometric properties of the PTSD Checklist (PCL). Behaviour Research and Therapy, 34, 669-673.

Blanchard, E.B., Kuhn, E., Rowell, D.L., Hickling, E.J., Wittrock, D., Rogers, R. L., Johnson M.R., \& Steckler D.C. (2004). Studies of the vicarious traumatization of college students by the September 11th attacks: Effects of proximity, exposure and connectedness. Behavior Research and Therapy, 42, 191-205.

Boscarino, J.A., Galea, S., Ahern, J., Resnick, H., \& Vlahov, D. (2002). Utilization of mental health services following the September 11th terrorist attacks in Manhattan, New York City. International Journal of Emergency Mental Health, 4, 143-155.

Bracha, H.S., Williams, A.E., Haynes, S.N., Kubany, E.S., Ralston, T.C, \& Yamashita, J.M. (2004). The STRS (Shortness of Breath, Tremulousness, Racing Heart, and Sweating): A brief checklist for acute distress with panic-like sympathetic indicators; development and factor structure. Annals of General Hospital Psychiatry, 3, 8.

Brewin, C.R. (2003). Posttraumatic stress disorder: Malady or myth? New Haven, CT: Yale University Press.
Brewin, C.R., Andrews, B., \& Rose, S. (2000). Fear, helplessness, and horror in posttraumatic stress disorder: Investigating DSM$I V$ Criterion A2 in victims of violent crime. Journal of Traumatic Stress, 13, 499-509.

Bryant, R.A., \& Harvey, A.G. (2000). Acute stress disorder: A handbook of theory, assessment, and treatment. Washington, DC: American Psychological Association.

Cano-Vindel, A., Miguel-Tobal, J. J., González-Ordi, H., \& Iruarrizaga, I. (2004). Los atentados terroristas del 11-M en Madrid: la proximidad de la residencia a las áreas afectadas. Ansiedad y Estrés, 10 (2-3), 181-194.

Conejero, S., de Rivera, J., Páez, D., \& Jiménez, A. (2004). Alteración afectiva personal, atmósfera emocional y clima emocional tras los atentados del 11 de marzo. Ansiedad y Estrés, 102-3, 299-312

ESEMeD/MHEDEA (2004). Prevalence of mental disorders in Europe: Results from the European Study of the Epidemiology of Mental Disorders (ESEMeD) Project. Acta Psychiatrica Scandinavica, 109, 21-27.

Fredrickson, B.L., Tugade, M.M., Waugh, C.E., \& Larkin, G.R. (2003). What good are positive emotions in crises? A prospective study of resilience and emotions following the terrorist attacks on the United States on September 11th, 2001. Journal of Personality and Social Psychology, 84, 365-376.

Galea, S., Ahern, J., Resnick, H., Kilpatrick, D., Bucuvalas, M., Gold, J., \& Vlahov D. (2002). Psychological sequelae of the September 11 terrorist attacks in New York City. New England Journal of Medicine, 346, 982-987.

Galea, S., Vlahov, D., Resnick, H., Ahern, J., Susser, E., Gold, J., Bucuvalas, M., \& Kilpatrick, D. (2003). Trends of probable post-traumatic stress disorder in New York City after the September 11 terrorist attacks. American Journal of Epidemiology, 158, 514-524.

González-Ordi, H., Miguel-Tobal, J.J., Cano-Vindel, A., \& Iruarrizaga, I. (2004). Efectos de la exposición a eventos traumáticos en personal de emergencias: consecuencias psicopatológicas del atentado terrorista del 11-M en Madrid. Ansiedad y Estrés, 10, 207-217.

Herman, D., Felton, C., \& Susser, E. (2002). Mental health needs in New York State following the September 11th attacks. Journal of Urban Health, 79, 322-331.

Iruarrizaga, I., Miguel-Tobal, J.J., Cano-Vindel, A., \& González, H. (2004). Consecuencias psicopatológicas tras el atentado terrorista del 11-M en Madrid en víctimas, familiares y allegados. Ansiedad y Estrés, 10, 195-206.

Kessler, R.C., Sonnega, A., Bromet, E., Hughes, M., \& Nelson, C.B. (1995). Posttraumatic stress disorder in the National Comorbidity Survey. Archives of General Psychiatry, 52, 1048-1060.

Kilpatrick, D.G., Resnick, H.S., Freedy, J.R., Pelcovitz, D., Resick, P., Roth, S., \& van der Kolk, B. (1998). The posttraumatic stress disorder field trial: Evaluation of the PTSD construct Criteria A through E. In T. Widiger, A. Frances, H. Pincus, R. Ross, M. First, W. Davis, \& M. Kline (Eds.), DSM-IV Sourcebook (Vol. 4, pp. 803-844). Washington, DC: American Psychiatric Press. 
Marshall, R.D., Spitzer, R., \& Liebowitz, M.R. (1999). Review and critique of the new DSM-IV diagnosis of acute stress disorder. American Journal of Psychiatry, 156, 1677-1685.

Matt, G.E., \& Vázquez, C. (2006). Psychological distress and resilience among distant witnesses of the 9/11 terrorist attacks: A natural experiment using multiple baseline and follow-up cohorts. Manuscript submitted for publication.

McCarter, L., \& Goldman, W. (2002). Use of psychotropics in two employee groups directly affected by the events of September 11. Psychiatric Services, 53, 1366-1368.

McNally, R.J., Bryant, R., \& Ehlers, A. (2003). Does early psychological intervention promote recovery from traumatic stress? Psychological Science in the Public Interest, 4, 45-79.

Miguel-Tobal, J.J., Cano-Vindel, A., Iruarrizaga, I., González, H., \& Galea, S. (2004). Consecuencias psicológicas de los atentados del 11-M en Madrid. Planteamiento general de los estudios y resultados en la población general. Ansiedad y Estrés, 10, 163-179.

Muñoz, M., Crespo, M., Pérez-Santos, E., \& Vázquez, J.J. (2004). Presencia de síntomas de estrés agudo en la población general de Madrid en la segunda semana tras el atentado terrorista del 11 de Marzo de 2004. Ansiedad y Estrés, 10, 147-161.

Murphy, R.T., Wismar, K., \& Freeman, K. (2003). Stress symptoms among African-American college students after the September 11, 2001 terrorist attacks. Journal of Nervous and Mental Disease, 191, 108-114.

Narrow, W.E., Rae, D.S., Robin, L.N., \& Regier, D.A. (2002). Revised prevalence estimates of mental disorders in the United States: Using a clinical significance criterion to reconcile 2 surveys' estimates. Archives of General Psychiatry, 59, 115123.

Norris, F., Byrne, C. M., Diaz, E., \& Kaniasty, K. (2001). 50,000 disaster victims speak: An empirical review of the empirical literature, 1981-2001. Report prepared for the National Center for PTSD and the Center for Mental Health Services.

North, C., Nixon S., Shariat, S., Mallonee, S., McMillen, J., Spitzanagel, E., \& Smith, E. (1999). Psychiatric disorders among survivors of the Oklahoma City bombing. Journal of the American Medical Association, 282, 755-762.

North, C.S., \& Pfefferbaum, B. (2002). Research on the mental health effects of terrorism. JAMA, 288, 633-636.

North, C.S., Smith, E.M., \& Spitznagel, E.L. (1994). Posttraumatic stress disorder in survivors of a mass shooting. American Journal of Psychiatry, 151, 82-88.

Office of Behavioral and Social Sciences Research. Assessing the effects of the attacks on America. Retrieved on August 30, 2002 from the National Institutes of Health Website: http://obssr.od.nih.gov/Activities/911/attack.htm/

Pérez Sales, P., Cervellón, P.,Vázquez, C., Vidales, D., \& Gaborit, M. (2005). Posttraumatic factors and resilience: The role of shelter management and survivors' attitudes after the earthquakes in El Salvador (2001). Journal of Applied Social Psychology, 15, 368-382.

Rosenheck, R., \& Fontana, A. (2003). Use of mental health services by veterans with PTSD after the terrorist attacks of September 11. American Journal of Psychiatry, 160, 1684-1690.
Rubin, G.J., Brewin, C.R., Greenberg, N., Simpson, J., \& Wessely, S. (2005). Psychological and behavioural reactions to the bombings in London on 7 July 2005: Cross-sectional survey of a representative sample of Londoners. Psychological Medicine, 331, 606. (BMJ, doi:10.1136/bmj.38583.728484.3A, published 26 August 2005).

Ruggiero, K.J., Del Ben, K., Scotti, J.R., \& Rabalais, A.E. (2003). Psychometric properties of the PTSD Checklist-Civilian Version. Journal of Traumatic Stress, 16, 495-502.

Sampedro, J. (2004, March 19). 150,000 madrileños sufrirán trastornos psicológicos leves. El País, p. 30.

Schlenger, W.E., Caddell, J.M., Ebert, L., Jordan, B.K., Rourke, K.M., Wilson, D., Thalji, L., Dennis, J.M., Fairbank, J.A., \& Kulka, R A. (2002). Psychological reactions to terrorist attacks: Findings from the National Study of Americans' Reactions to September 11. JAMA, 288, 581-588.

Schuster, M.A., Stein, B.D., Jaycox, L., Collins, R.L., Marshall, G.N., Elliott, M.N., Zhou, A.J., Kanouse, D.E., Morrison, J.L., \& Berry, S.H. (2001). A national survey of stress reactions after the September 11, 2001, terrorist attacks. New England Journal of Medicine, 345, 1507-1512.

Shalev, A.Y. (2004). Further lessons from 9/11: Does stress equal trauma? Psychiatry, 67, 174-177.

Silver, R.C., Holman, E.A., McIntosh, D.N., Poulin, M., \& GilRivas, V. (2002). Nationwide longitudinal study of psychological responses to September 11. JAMA, 288, 1235-1244.

Southwick, S.M., \& Charney, D.S. (2004). Responses to trauma: Normal reactions or pathological symptoms. Psychiatry, 67, 170-173.

Sprang, G. (1999). Post-disaster stress following the Oklahoma City bombing: An examination of three community groups. Journal of Interpersonal Violence, 14, 169-183.

Stein, B.D., Elliott, M.N., Jaycox, L., Collins, R.L., Berry, S.H., Klein, D.J., \& Schuster, M.A. (2004). A national longitudinal study of the psychological consequences of the September 11, 2001 terrorist attacks: Reactions, impairment, and help-seeking. Psychiatry, 67, 105-117.

Stephenson, J. (2001). Medical, mental health communities mobilize to cope with terror's psychological aftermath. JAMA, 286, 1823-1825.

Vázquez, C. (2005). Stress reactions of the general population after the terrorist attacks of S11 (USA) and M11 (Madrid, Spain): Myths and realities. Annuary of Clinical and Health Psychology, 1, 9-25. (http://www.us.es/apcs/vollesp.htm).

Vázquez, C., Cervellón, P., Pérez Sales, P., Vidales, D., \& Gaborit, M. (2005). Positive emotions in earthquake survivors in El Salvador (2001). Journal of Anxiety Disorders, 19, 313-328.

Weathers, F.W., Litz, B.T., Herman, D.S., Huska, J.A., \& Keane, T.M. (1993, October). The PTSD Checklist: Reliability, validity and diagnostic utility. Paper presented at the annual meeting of the International Society for Traumatic Stress Studies, San Antonio, TX.

Wessely, S. (2004). When being upset is not a mental problem. Psychiatry, 67, 153-157.

Received, October, 20, 2005

Review received, January, 10, 2006 Accepted, January, 16, 2006 